Pacific Journal of Mathematic 


\title{
ON THE DIVISIBILITY OF THE CLASS NUMBER OF QUADRATIC FIELDS
}

\author{
N. C. AnKeny and S. Chowla
}

1. Introduction. It is well known that there exist infinitely many quadratic extensions of the rationals each with class number divisible by 2 . In fact, if the discriminant of the field contains more than two prime factors, then 2 divides the class number. Max Gut [1] generalized this result to show that there exist infinitely many quadratic imaginary fields each with class number divisible by 3 . In this present paper we prove that there exist infinitely many quadratic imaginary fields each with class number divisible by $g$ where $g$ is any given rational integer.

The method extends to yield certain results about quadratic real fields, but these are not as sharp as on quadratic imaginary fields.

2. Theorem. In the following we may assume without loss of generality that $g$ is positive, sufficiently large, and even.

Lemma 1. Denote by $N$ the number of square-free integers of the form

$$
3^{g}-x^{2} \text {, where } 2 \mid x, 0<x<\left(2.3^{g-1}\right)^{1 / 2} \text {. }
$$

Then, for g sufficiently large,

$$
N \geq \frac{1}{25} 3^{g / 2} .
$$

Proof. Denote by $d$ the expression

$$
d=3^{g}-x^{2},
$$

where

$$
2 \mid x, 0<x<\left(2 \cdot 3^{g-1}\right)^{1 / 2} .
$$

Received September 28, 1953.

Pacific J. Math. 5 (1955), 321-324 
The number of such $d$ is

$$
\frac{1}{2}\left(2 \cdot 3^{g-1}\right)^{1 / 2}+O(1) \text {. }
$$

As $2 \mid x$, none of the $d$ 's are divisible by 2 . The number of $d$ divisible by 3 , and, hence, by 9 , is less than

$$
\frac{1}{6}\left(2 \cdot 3^{g-1}\right)^{1 / 2}+O(1)
$$

For $p$ an odd prime greater than 3 , the number of $d$ divisible by $p^{2}$ is less than

$$
\frac{1}{2 p^{2}}\left(2 \cdot 3^{g-1}\right)^{1 / 2}+2
$$

Hence the number of square-free $d$ is

$$
\begin{aligned}
N & \left.\geq \frac{1}{2}\left(2 \cdot 3^{g-1}\right)^{1 / 2}-\frac{1}{6}\left(2 \cdot 3^{g-1}\right)^{1 / 2}+O(1)-\sum_{\substack{p \geq 5 \\
p^{2}<3^{g}}} \frac{1}{2 p^{2}}\left(2 \cdot 3^{g-1}\right)^{1 / 2}+2\right) \\
& \geq \frac{1}{2}\left(2 \cdot 3^{g-1}\right)^{1 / 2}\left(1-\frac{1}{3}-\sum_{p \geq 5} \frac{1}{p^{2}}\right)-2 \sum_{p^{2}<3^{g}} 1+O(1) \\
& \geq \frac{1}{2}\left(2 \cdot 3^{g-1}\right)^{1 / 2}\left(1-\frac{1}{3}-\sum_{n=5} \frac{1}{n^{2}}\right) \pm O\left(\frac{1}{g} 3^{g / 2}\right),
\end{aligned}
$$

by the prime-number theorem. Hence

$$
N \geq \frac{1}{2}\left(2 \cdot 3^{g-1}\right)^{1 / 2}\left(1-\frac{1}{3}-\frac{1}{4}\right)+O\left(\frac{1}{g} 3^{g / 2}\right) \geq \frac{1}{25} 3^{g / 2} .
$$

THEOREM 1. For the square-free integers $d$ which satisfy (1) and (2) we have $\mathrm{g} \mid \mathrm{h}$, where $h$ denotes the class number of the field $R(\sqrt{-d})$.

Proof. Consider the quadratic extension of the rationals $R(\sqrt{-d})$. Since

$$
3^{g}=x^{2}+d
$$

where $x$ is prime to 3 as $d$ is square free, we see that 


$$
x^{2}+d \equiv O(\bmod 3)
$$

Hence, by the well-known criterion for the splitting of rational primes in quadratic extensions, $(3)=P_{1} P_{2}$ where (3) denotes the principal ideal generated by 3 in $R(\sqrt{-d})$, and $P_{1}, P_{2}$ are two distinct conjugate prime ideals in $R(\sqrt{-d})$.

Let $m$ be the least positive integer such that $P_{1}^{m}$ is a principal ideal in $R(\sqrt{-d})$. If possible let $m<g$, and $P_{1}^{m}=(\alpha)$ for some integer $\alpha \in R(\sqrt{-d})$. Since $2 \mid g$, we have $2 \mid x$, and, by $(1), d \equiv 1(\bmod 4)$. Then

$$
a=u+v \sqrt{-d}
$$

for rational integers $u$ and $v$.

Then

$$
\left(3^{m}\right)=P_{1}^{m} P_{2}^{m}=(u+v \sqrt{-d})(u-v \sqrt{-d})=\left(u^{2}+v^{2} d\right),
$$

or

$$
3^{m}=u^{2}+v^{2} d .
$$

By (1) and (2), we have $d>3^{g-1}$; but if $m<g$, (3) implies

$$
3^{g-1} \geq u^{2}+v^{2} d
$$

so $v=0$. But then

$$
P_{1}^{m}=(u), P_{2}^{m}=(u), \quad \text { or } \quad P_{1}^{m}=P_{2}^{m}, P_{1}=P_{2} \text {, }
$$

which is false as $P_{1}, P_{2}$ are two distinct prime ideals in $R(\sqrt{-d})$.

Thus we have shown that $m \geq g$; but as $3^{g}=x^{2}+d, m=g$. Hence, there exists in $R(\sqrt{-d})$ a prime ideal $P_{1}$ whose $g$ th power but none lower is a principal ideal. This immediately implies $g \mid h$.

3. Application. To show that there exist infinitely many fields each with class number divisible by $g$, we proceed as follows. Theorem 1 shows that there are at least $(1 / 25) 3^{g / 2}$ with class number divisible by $g$. Let $g^{t}=g_{1}$ be such that the class number of none of these fields is divisible by $g_{1}$. Then, as before, we find at least $(1 / 25) 3^{g_{1} / 2}$ fields with class number divisible by $g_{1}$. These fields must be distinct from the previous fields. Repeating this method we see there exist infinitely many quadratic fields with class number divisible 
by $g$.

4. A further result. We shall prove:

THEOREM 2. If $d$ is square free number of the form $d=n^{2 g}+1$, where $n>4$, then $g \mid h$, where $h$ is the class number of the field $R(\sqrt{d})$.

Proof. We need only outline the proof of Theorem 2, as in most aspects it is very similar to the proof of Theorem 1 . We first show that

$$
(n)=\mathfrak{2} \mathfrak{Z}^{\prime} \text { in } R(\sqrt{d}) \text {, }
$$

where $\mathscr{C}^{2}, \mathfrak{C}^{\circ}$ are two relatively prime conjugate ideals. We then show that $u^{2}-d v^{2}(u, v$ integers $)$ represents no integer other than 0 and 1 whose absolute value is less than $\sqrt{d}$. This follows from the fact that $d$ is of the form $d=w^{2}+l$. Hence the least power of $\mathscr{U}$ which is a principal ideal is the $g$ th power. This immediately implies $g \mid h$.

The interest of Theorem 2 is somewhat lessened by the fact that it is unknown at present if there exists an infinite number of square-free numbers of the form $n^{2 g}+1$. Hence we are unable to prove a theorem similar to Theorem 1 with regard to quadratic real extensions of the rationals.

\section{ReFERENCE}

1. Max Gut, Kubische Klass enkörper über quadratischimaginären Grundkörpern, Nieuw Arch. Wiskunde (2) 23 (1951), 185 - 189.

JOHNS HOPKINS UNIVERSITY,

UNIVERSITY OF COLORADO 


\section{PACIFIC JOURNAL OF MATHEMATICS}

\section{EDITORS}

\author{
H.L. ROYDEN \\ Stanford University \\ Stanford, California \\ E. HEWITT \\ University of Washington \\ Seattle 5, Washington
}

\author{
R. P. DILWORTH \\ California Institute of Technology \\ Pasadena 4, California \\ * Alfred Horn \\ University of California \\ Los Angeles 24, California
}

\section{ASSOCIATE EDITORS}

\section{H, BUSEMANN \\ HERBERT FEDERER}

MARSHALL HALL

\section{P.R. HALMOS \\ HEINZ HOPF}

ALFRED HORN

\author{
R.D. JAMES \\ BØRGE JESSEN \\ PAUL LÉVY
}

GEORGE PÓLYA

J.J. STOKER

KOSAKU YOSIDA

\section{SPONSORS}

UNIVERSITY OF BRITISH COLUMBIA

UNIVERSITY OF SOUTHERN CALIFORNIA

CALIFORNIA INSTITUTE OF TECHNOLOGY

UNIVERSITY OF CALIFORNIA, BER KELEY

STANFORD RESEARCH INSTITUTE

STANFORD UNIVERSITY

UNIVERSITY OF CALIFORNIA, DAVIS

UNIVERSITY OF. UTAH

UNIVERSITY OF CALIFORNIA, LOS ANGELES

WASHINGTON STATE COLLEGE

UNIVERSITY OF CALIFORNIA, SANTA BARBARA

UNIVERSITY OF WASHINGTON

MONTANA STATE UNIVERSITY

UNIVERSITY OF NEVADA

OREGON STATE COLLEGE

AMERICAN MATHEMATICAL SOCIETY

HUGHES AIRCRAFT COMPANY

UNIVERSITY OF OREGON

SHELL DEVELOPMENT COMPANY

\section{UNIVERSTTY OF SOUTHERN CALIFORNIA}

Mathematical papers intended for publication in the Pacific Journal of Mathematics should be typewritten (double spaced), and the author should keep a complete copy. Manuscripts may be sent to any of the editors. Manuscripts intended for the outgoing editors should be sent to their successors. All other communications to the editors should be addressed to the managing editor, Alfred Horn, at the University of California Los Angeles 24, California.

50 reprints of each article are furnished free of charge; additional copies may be obtained at cost in multiples of 50 .

The Pacific Journal of Mathematics is published quarterly, in March, June, September, and December. The price per volume (4 numbers) is $\$ 12.00$; single issues, $\$ 3.50$; back numbers (Volumes $1,2,3$ ) are available at $\$ 2.50$ per copy. Special price to individual faculty members of supporting institutions and to individual members of the American Mathematical Society: $\$ 4.00$ per volume; single issues, $\$ 1.25$.

Subscriptions, orders for back numbers, and changes of address should be sent to the publishers, University of California Press, Berkeley 4, California.

Printed at Ann Arbor, Michigan. Entered as second class matter at the Post Office, Berkeley, California.

* During the absence of E.G. Straus.

UNIVERSITY OF CALIFORNIA PRESS - BERKELEY AND LOS ANGELES 


\section{Pacific Journal of Mathematics}

\section{Vol. 5, No. $3 \quad$ November, 1955}

Nesmith Cornett Ankeny and S. Chowla, On the divisibility of the class number of quadratic fields ............................. 321

Cecil Edmund Burgess, Collections and sequences of continua in the plane ........................................ 325

Jane Smiley Cronin Scanlon, The Dirichlet problem for nonlinear elliptic equations....................................... 335

Arieh Dvoretzky, A converse of Helly's theorem on convex sets ......... 345

Branko Grünbaum, On a theorem of L. A. Santaló................ 351

Moshe Shimrat, Simple proof of a theorem of P. Kirchberger .......... 361

Michael Oser Rabin, A note on Helly's theorem . ................... 363

Robert E. Edwards, On factor functions . . ................... 367

Robert E. Edwards, On certain algebras of measures ............... 379

Harley M. Flanders, Methods in affine connection theory.............. 391

Alfred Huber, The reflection principle for polyharmonic functions ........ 433

Geoffrey Stuart Stephen Ludford, Generalised Riemann invariants ....... 441

Ralph Gordon Selfridge, Generalized Walsh transforms............. 451 